\title{
Approach to the epidemiology of venomous bites in Spain
}

\author{
Zuleika Saz-Parkinson ${ }^{\mathrm{a}, *}$, Miguel del Pino Luengo ${ }^{\mathrm{b}}$, Teresa López-Cuadrado ${ }^{\mathrm{c}}$, \\ Dionisio Andújar ${ }^{\mathrm{d}}$, Rocío Carmona-Alférez ${ }^{\mathrm{a}}$, Ricardo Martín Flores ${ }^{\mathrm{a}}$, José María Amate ${ }^{\mathrm{a}}$ \\ ${ }^{a}$ Agencia de Evaluación de Tecnologías Sanitarias, Instituto de Salud Carlos III, Avenida Monforte de Lemos 5, 28029 Madrid, Spain \\ ${ }^{\mathrm{b}}$ I.E.S Eijo y Garay, Madrid, Spain \\ ${ }^{\mathrm{c}}$ Centro Nacional de Epidemiología, Instituto de Salud Carlos III, Avenida Monforte de Lemos 5, 28029 Madrid, Spain \\ d Universität Hohenheim, Institute Phytomedice, Dept Weed Science 360B, D-70599 Stuttgart, Germany
}

\section{A R T I C L E I N F O}

\section{Article history:}

Received 27 February 2012

Received in revised form 14 March 2012

Accepted 21 March 2012

Available online 30 March 2012

\section{Keywords:}

Bites and stings

Envenomations, Snake

Epidemiology

Humans

Hospitalization

National Hospital Discharge Survey

\begin{abstract}
A B S T R A C T
This review presents a geographic distribution of the three autochthonous venomous snake species, which are the only viperids present in Spain, among the Iberian fauna: Vipera aspid; Vipera seoianei and Vipera latasti.

This is followed by a detailed descriptive analysis of hospital care provided to patients admitted into hospital due to venomous bites, in the period from 1997 to 2009, using the data from the Spanish hospital discharge registry database.

This analysis reveals that in Spain, during this period, 1649 cases were recorded, which means that hospital care was required for more than one hundred cases per year, of which nearly $1 \%$ of the cases resulted in death.

Cases were recorded in all the Autonomous communities, but more than half $(54,14 \%)$ were concentrated in the following four regions: Cataluña, Castilla and León, Galicia and Andalucía. It is notable that this concentration of cases is not associated only with the population demographics of the community, but is also the result of the concurrence of very diverse factors of exposure including: habitat of venomous fauna, volume of rural population, farming activities, and practice of outdoor leisure activities.

We also carried out a gross economic calculation for the use of hospital resources by each snakebite case requiring hospital care in Spain, which provided us with an approximate figure of $2000 €$ per case.
\end{abstract}

(c) 2012 Elsevier Ltd. All rights reserved.

\section{Introduction}

In Spain, venomous bites are a rare medical emergency that could perhaps be considered an "ultra-orphan" condition according to the most modern terminology, but that we will consider "orphan" following the current legal consideration in the European Union.

The biogeographical situation of Spain, particularly as it refers to its bioclimatic position as a bridge between the Paleartic and Ethiopian kingdoms, makes this a very rich region, not only in its biodiversity, but also in endemisms.

\footnotetext{
* Corresponding author. Tel.: +34 918222135; fax: +34 913877841.

E-mail address: zuleika@isciii.es (Z. Saz-Parkinson).
}

In consequence, there is a presence of species that belong to the Ethiopian Paleoclimatic Region, among which we find several with varied venoms and poisons. The Atlantic and Mediterranean climates that affect most of the Spanish regions, with milder average temperatures than the tropical climate, determine that the autochthonous venomous species are not as dangerous as their closer Ethiopian relatives. This follows the so-called "Physiological rule" of Van T'hoff, which establishes metabolism intensity as well as that of the venom's toxicity as a function of the rise in environmental temperature.

Apart from the imported exotic species kept in collector's terrariums, zoological parks or research centres, the venomous animals of the autochthonous Iberian fauna 
belong to the zoological classes Arachnida and Reptilia. Among the first are spiders, ticks and scorpions but, although all their species have poison, in the Spanish ones their activity is not such that, except in small children or the presence of other complications, hospital assistance is necessary, but symptomatic treatment is required. On the other hand, among reptiles, there are three autochthonous venomous species which are the only viperids present among Iberian fauna: Vipera aspid; Vipera seoianei and Vipera latasti.

$V$. aspid inhabits a wide range of habitats, particularly in humid mid-mountain areas, although they can spread to the upper mountain, reaching over $2500 \mathrm{~m}$ in altitude in the Pyrenees. The venom is made up of proteolytic enzymes, phospholipases, hyalurinidase, haemorrhagic factors, accelerators and inhibitors of the coagulation cascade and, different to the specimens from the South of France, L-amino oxidases. Their toxicity varies greatly among the different populations, being especially high in the Basque Country, up to Rioja and Burgos (MartínezFreiría et al., 2009).

V. seoianei was initially described as Vipera berus seoanei by Lataste ei 1879 , but marked differences in the external morphology have led to its taxonomy being revised in 1976 and being classified a different species (Saint-Girons and Duguy, 1976; Duguy and Saint-Girons, 1976). Its habitat encompasses large forests in mountain and humid areas, being one of the most abundant snakes in the Cantabric area up to Galicia and North of Portugal. Given that it is a good swimmer, it is the most aquatic of all vipers, it is able to cross rivers and streams and thus increase its area of distribution. The toxicity of its venom is quite variable: it is reduced in the populations of the most oriental regions (Basque Country and Cantabria) and high in the most western regions (Galicia and North of León) (Brito et al., 2009).

V.latasti. It spreads practically around the entire peninsula, except for the Cantabric area and Pyrenees. It is frequent in sandy floors and dunes at sea level, but also reaches the mountainous systems. Overall, it shows a preference for warm areas in fairly untouched settings, without competitor species and scarce human density. The toxicity of its venom is usually less than that of the previously mentioned species; however, the quantity that is inoculated in the bite is significantly greater, which causes the seriousness of the episode. On the other hand, the young specimens normally inject smaller quantities of poison, though it is more concentrated (Brito et al., 2011).

The objective of this study is to present the epidemiology of venomous snakebites in Spain in the period from 1997 to 2009, based on those bites that have required hospital care.

\section{Methods}

\subsection{Descriptive analysis of hospital care}

Having previously received the corresponding authorization access, we exploited the registry of the "Conjunto Mínimo Básico de Datos (CMBD) al alta hospitalaria" (hospital discharge registry), of the Ministry of Health and
Social Policy, during the period from 1997 to 2009, choosing the following variables: Year of Discharge; Code of the Hospital's Autonomous Community; Autonomous Community of the Hospital; Code of the Main Diagnosis; Description of the Main Diagnosis; Sex Code; Sex; Age; Code on Admittance; Type of Admittance; Code on Discharge; Type of Discharge; Patients; Cases and Length of Stays.

The filters used to extract the registries of interest were the following:

- Years: 1997 to 2009, inclusively.

- ICD-9 Diagnosis: 989.5 Toxic effect of; venom, Bites of venomous snakes, lizards, and spiders, Tick paralysis, whether it be main or secondary diagnosis. ${ }^{1}$

Statistical analysis was undertaken using the software package STATA 11.1 (2009; StataCorp College Station, Texas 77845 USA).

Given that the variable "patient" existed, it has been transformed in the database by processing each one of the registers, each case, as a patient. A total of 1.649 registers were obtained, and after processing the data according to the previously mentioned variables, the following results were obtained.

\section{Results}

Following the process described in the previous section, we obtain a database with 1.649 registers reflecting all hospital admissions, between 1997 and 2009, into the National Health System where a diagnosis of venomous bite (ICD-9: 989.5) appears.

The annual cases are distributed according to Fig. 1, where it can be observed that the great majority of these bites are due to an emergency admission (accounting for $94 \%$ of all admissions), while only $6 \%$ are programmed admissions, and these usually correspond to transfers from one centre to another.

The ICD-9 code 989.5 is not present in all admission cases as a primary diagnosis, but appears in approximately $84 \%$ of cases while $16 \%$ of cases are not admitted into hospital due to a primary diagnosis of a venomous bite, but are admitted due to other symptoms such as lymphedema, lower limb edema, etc. but when the physical examination is carefully carried out in hospital, the bite is identified, and thus it appears as a secondary diagnosis.

\footnotetext{
${ }^{1}$ Main diagnosis: Considered to be that which, after examination of the patient, it is established that it was the reason for admitting the patient into hospital, according to the criteria of the clinical service or the medical professional who examined the patient, even though important complications or even independent complaints could arise during the patient's stay which would be indicated as secondary diagnoses. Diagnoses are coded according to the 9th edition of the International Classification of Diseases (ICD-9) in the edition officially translated for the National Health System by the Ministry of Health, for the corresponding year. Secondary Diagnoses: Those diagnoses (up to 13) that despite not being the main one, coexist with it at the time of hospital admittance or develop during the hospital stay, and affect the duration of the stay or the treatment provided. Those diagnoses related to a previous episode and which do not affect the current admission should be excluded. They are also coded using the ICD-9.
} 


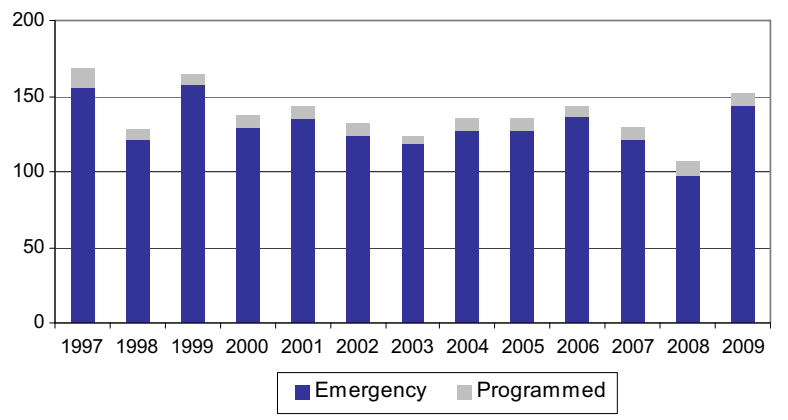

Fig. 1. Annual case distribution.

In addition to these different diagnoses when the patient is admitted into hospital, there are also a variety of reasons for hospital discharge (Fig. 2). The great majority of cases, 95\%, are resolved and the patient is allowed to go home, but $1.78 \%$ of cases are transferred to another hospital centre, almost $1 \%$ of cases die, and $0.78 \%$ cases voluntarily leave the hospital. The remaining cases are mainly due to non-coded or incorrectly coded cases.

In order to examine how the venomous bite cases are distributed around all the provinces of Spain, we see the following map (Fig. 3), where the four different shades of red represent the different quartiles.

To examine how the distribution of bite cases that have required hospital care in Spain relates to the geographic distribution of the three viper species in Spain, we see the following (Fig. 4).

There are four Autonomous Communities (Cataluña, Castilla y León, Galicia and Andalucía) that represent more than $50 \%$ of the total cases in Spain as seen in the red curve on Fig. 5, which shows all accumulated cases.

If we now look at the incidence by age group, we find that the greatest number of cases is found between 5 and 14 years of age, followed by those older than 65 years of age (Fig. 6).

With regards to gender, there are always twice, and in some cases three times, as many bites in men as in women. Although in infants bites are found to occur more equally

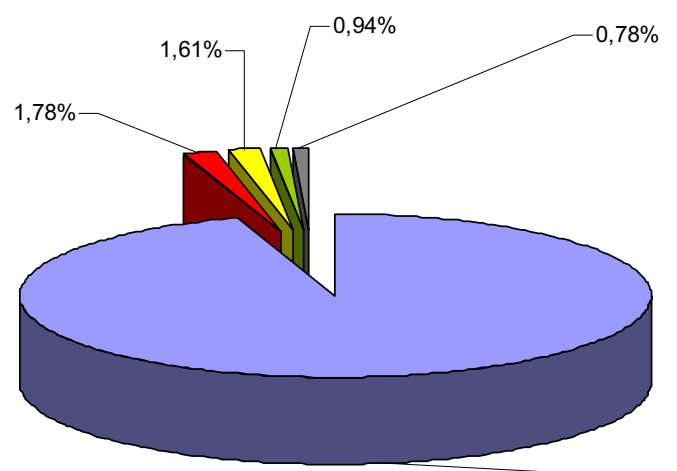

$\square$ Home $\square$ Transfer $\square$ Others $\square$ Exitus $\square$ Voluntary

Fig. 2. Reasons for hospital discharge.

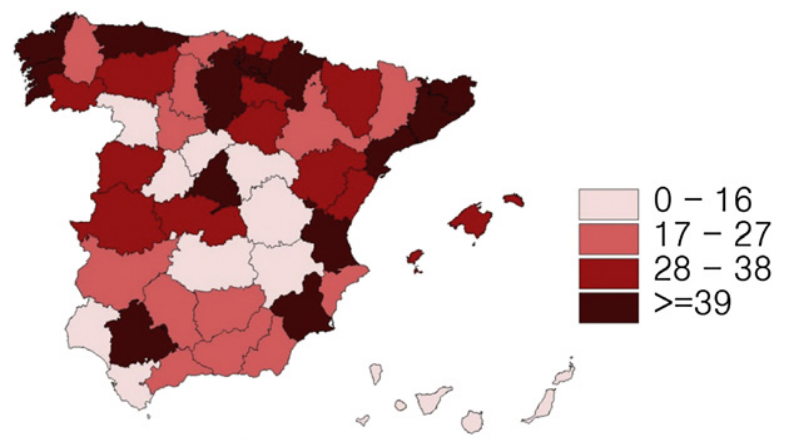

Fig. 3. Map of Spain with case distribution according to provinces.

between sexes, there are more bites in males than females with the difference between the sexes becoming more pronounced as age increases until the age of 45 when the trend starts to decrease, due mainly to the greater presence of women than men in those more advanced age groups. Overall, $70 \%$ of bites take place in males and $30 \%$ in women (Fig. 7).

As was previously mentioned (Fig. 2), there is approximately 1 death per year which represents approximately $1 \%$ of all bites, although we observed that in the years 1998-2000 there were three deaths each year, while in the years 2001, 2002 and 2008 there were none.

If we examine how these deaths are distributed according to the autonomous community where they were registered (Fig. 8), we observe that most of them, five, occur in Madrid.

The distribution of bite cases according to the size of the hospital, as a function of the number of hospital beds available, which has provided care to these individuals can be seen in Fig. 9. In the small hospital category, under 200 beds, we find regional hospitals which are probably those hospitals closer to where the bites occur. These hospitals receive $22 \%$ cases, while more urban hospitals with $200-$ 500 beds receive $16 \%$ of bite cases and as hospital size increases so do the number of cases they attend. This is mainly seen in the hospitals with $500-1000$ beds, which attend almost $36 \%$ cases.

Finally, we attempted to carry out a gross economic calculation of what hospital care for venomous snakebites would entail in Spain. For this, we took into account the total number of days a hospital bed was occupied in the period 1997-2009 (9016 days), the number of cases attended in this 13 year period, with an average stay per case of approximately 5 days, and the average cost of a hospital bed per day (approximately $415 €$ ) which, therefore, results in a cost of approximately $2,000 €$ per snakebite case.

\section{Discussion}

The number of cases of venomous snakebites requiring hospital care in the period from 1997 to 2009 has remained fairly constant at approximately 130 cases per year, with slight increases in the years 1997, 1999 and 2009. The majority of these cases (94\%) were admitted into hospital as 


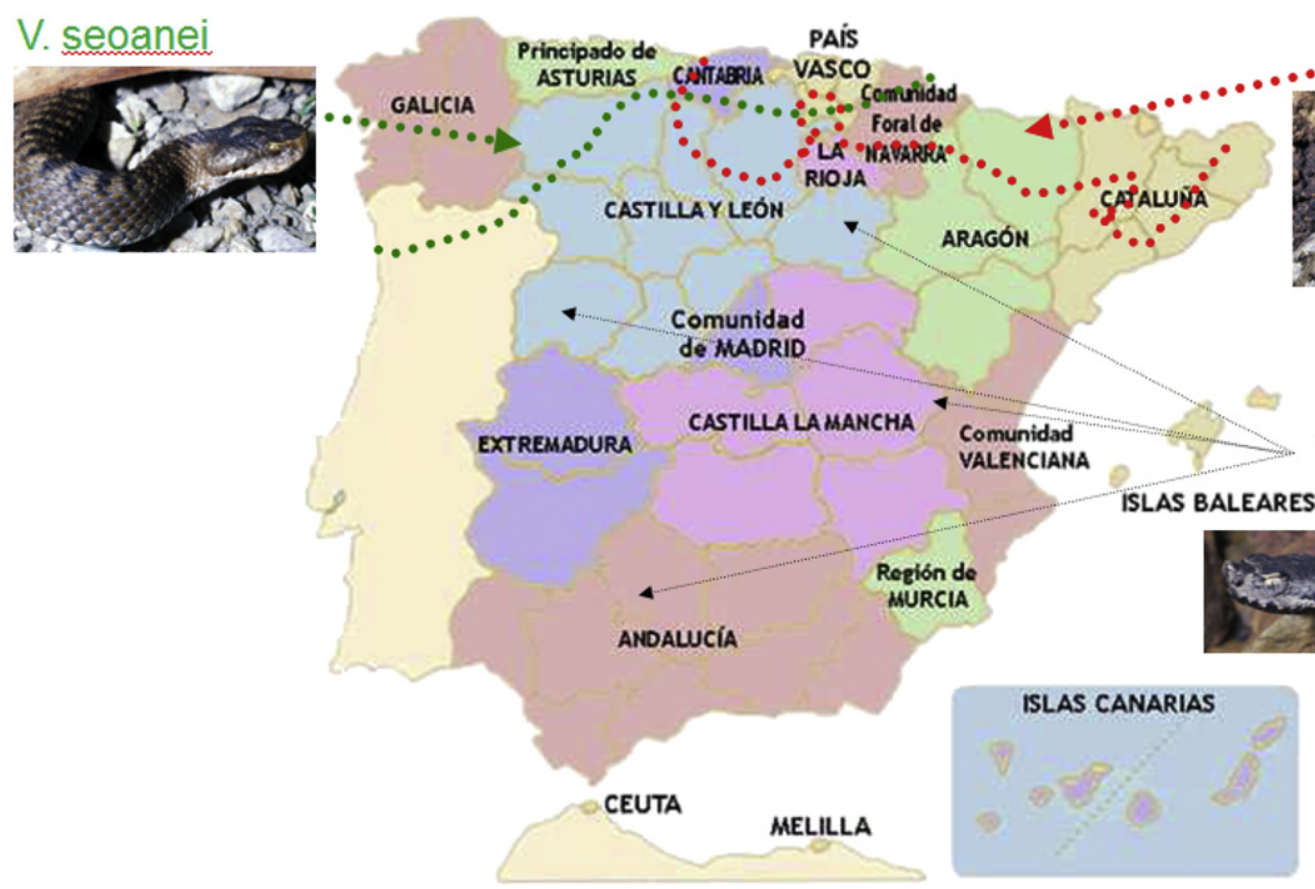

Fig. 4. Geographical distribution of the autochthonous venomous vipers in Spain.

an emergency admission, and 95\% of cases were resolved with the patient being able to return to his/her home, while less than $1 \%$ resulted in the death of the patient.

We found no correlation between the incidence of snakebites and population density. For example Cataluña and Andalucía are demographically densely populated regions (about 15 million inhabitants together) while Galicia and Castilla y León have only about 2 million inhabitants, but both pairs of AACC have approximately the same number of bite cases. This is similar as has been observed in a systematic review of snakebites in Europe (Chippaux, 2012), and suggests that more complex mechanisms are involved in these attacks, such as exposure, geographic distribution of the different species, degree of rurality of the population, intensity of different agricultural activities, outdoor leisure activities, etc.

Regarding the case distribution by age, the large number of cases between the ages of 5-14 can be explained by, on the one hand, the greater vulnerability of this age group, as well as those below 5 years of age, where the bite can become more serious and require hospital treatment, but also perhaps due to the greater irresponsibility of children this age which may be more careless, as well as the greater presence of children in this age group carrying out outdoor

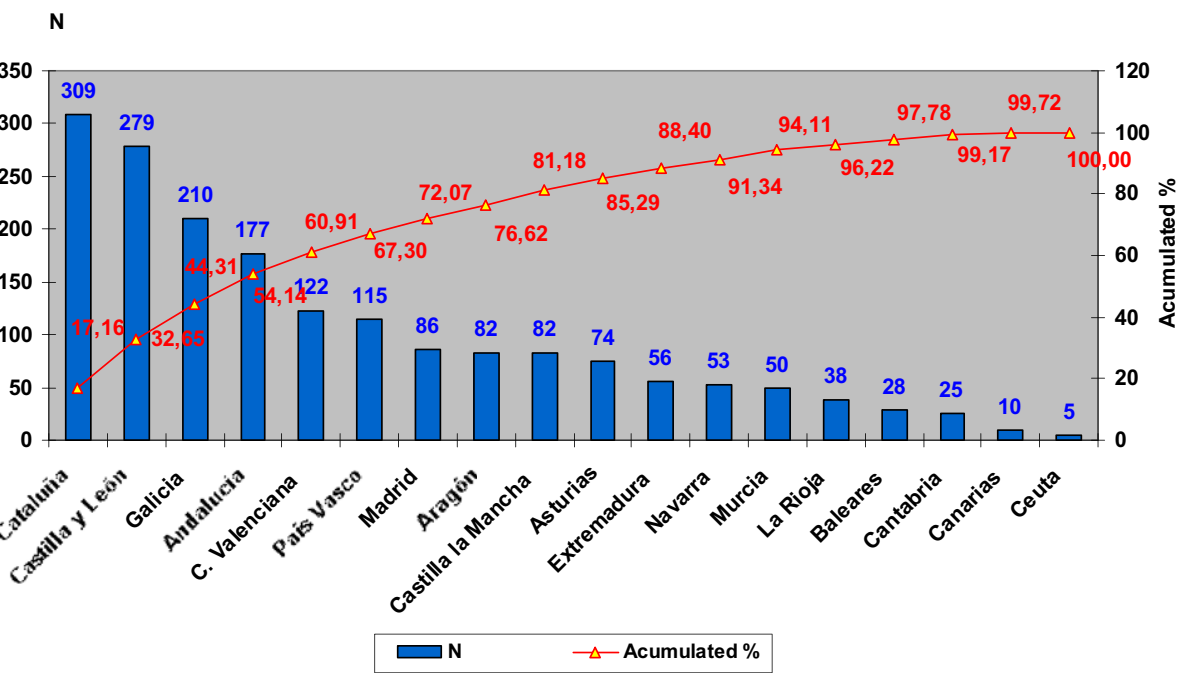

Fig. 5. Case distribution according to Autonomous Community. 


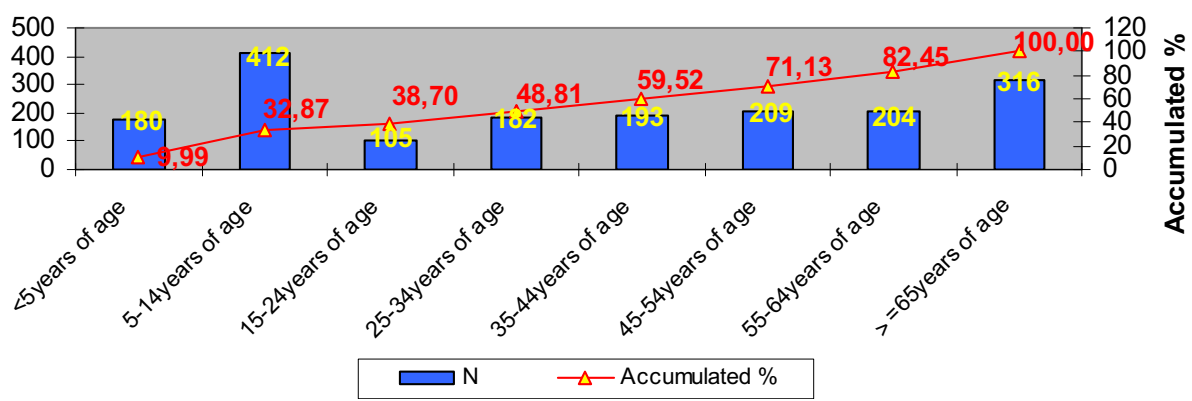

Fig. 6. Case distribution according to age group.

activities. Between the ages of $15-24$, it is more common for youth to engage in indoor activities instead of outdoor activities which may explain the drastic decrease in the incidence in this age group. Beyond this age there is a certain regularity in the number of cases which increase in the final age group of individuals over the age of 65 , which could be explained, on the one hand by the fact that the majority of people living in rural areas are over the age of 65 , and perhaps also the increasing presence of other health conditions which may increase the seriousness of the bite. In a German study (Prenzel et al., 2008), studying the clinical picture, diagnosis and management of adder bites, they also found an overrepresentation in their population of children and elderly patients.

Regarding the greater occurrence of bites in males than females, our data is similar to other published studies that have also used hospital or practitioner-reported data where approximately $67 \%$ of cases were male (Petite, 2005).

The fact that most deaths due to poisonous bites in the period from 1997 to 2009 have occurred in Madrid, despite the fact that this autonomous community is not the one with most bites could be explained by the fact that many of the most serious patients from other autonomous communities are transferred to major hospitals in Madrid for their care. Galicia, Andalucía and Cataluña also have more than the average number of reported deaths, but in these autonomous communities there is a larger number of bites registered as compared with the remaining regions.

The distribution of bite cases according to the size of the hospital, shows us that the hospitals which are probably closer to where bites actually take place (hospitals with fewer than 200 beds) receive 22\% cases, while larger hospitals, with 500-1000 beds, which are found in most provinces attend the largest number of cases (36\% of all cases), perhaps due mainly to the patient's fear, and his/her preference of travelling a little further away but be seen in a larger hospital with more resources.

The gross economic calculation for the use of hospital resources by each snakebite case requiring hospital care in Spain, provided us with an approximate figure of $2000 €$ per case, which of course would be vary variable depending on, among other things, the patient's comorbidities, the services used in the hospital and the size of the hospital.

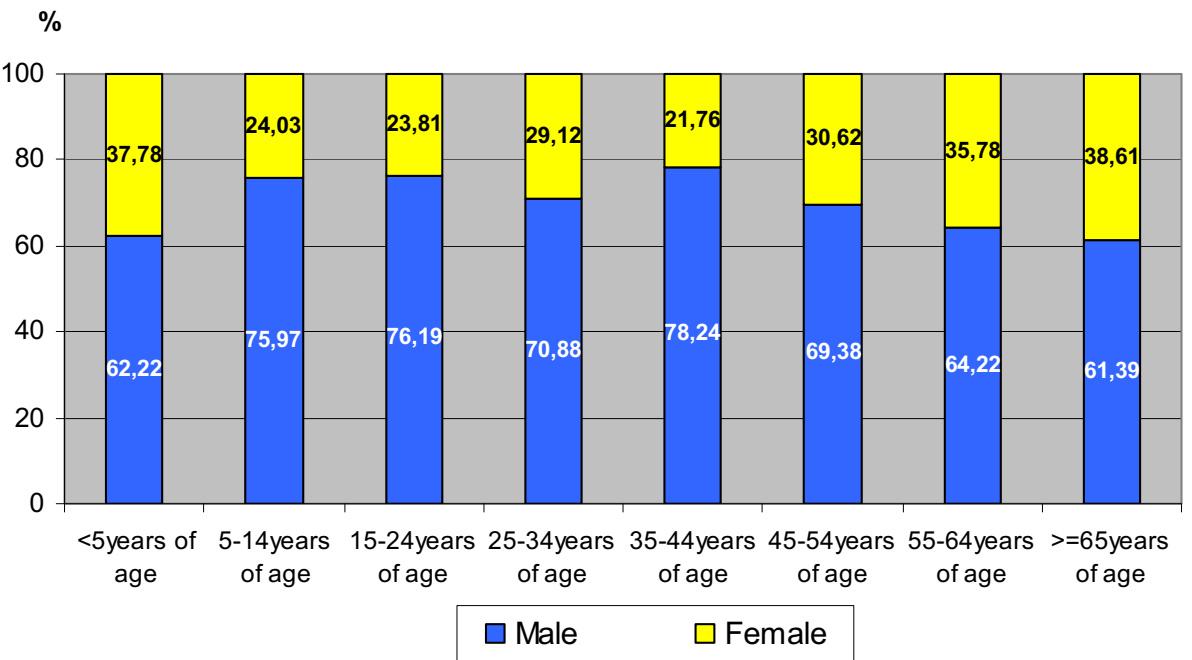

Fig. 7. Case distribution according to gender. 


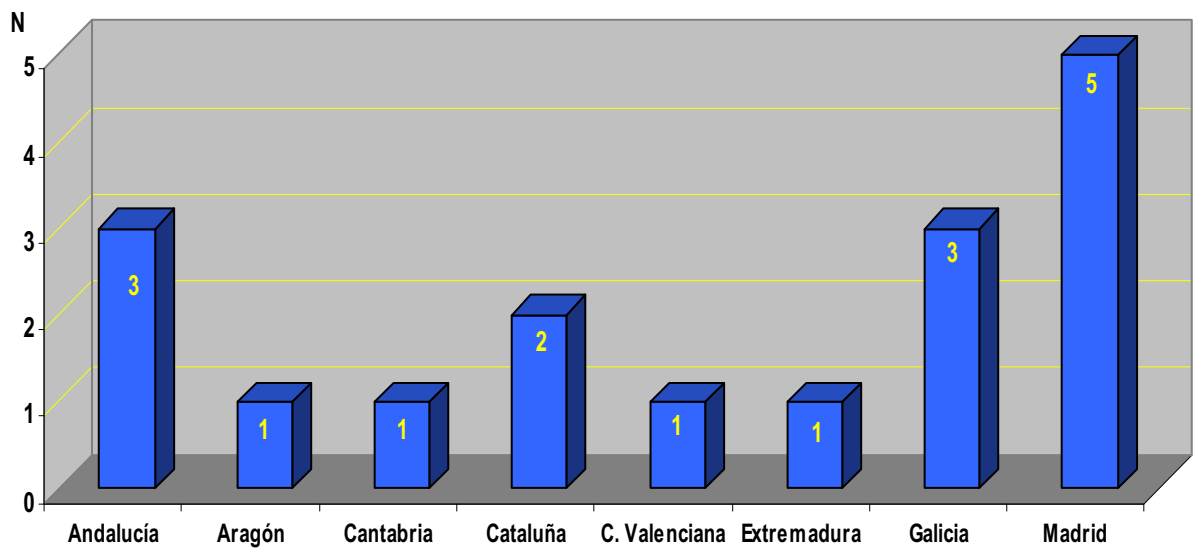

Fig. 8. Distribution of deaths according to Autonomous Community.

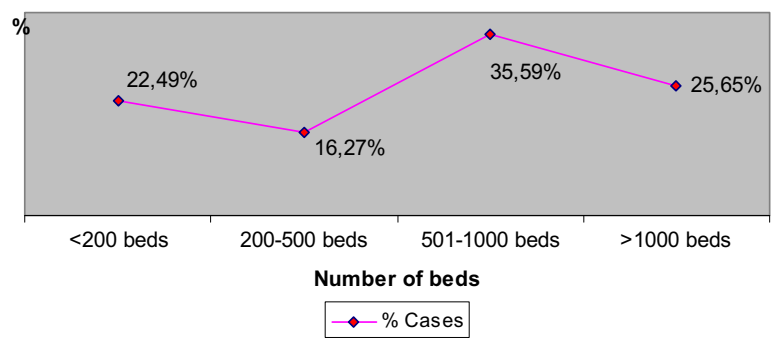

Fig. 9. Distribution of cases according to hospital size.

\section{Acknowledgements}

We would like to thank Dra. María Ángeles Gogorcena Aoiz, from the Institute of Health Information of the Ministry of Health, Social Services and Equality, for her help in accessing the data from the hospital discharge registry database. We would also like to thank Mr. Mario García París, Mr. Jesús Dorda and Ms. Soledad Alonso, from the National Museum of Natural Sciences of Madrid who have provided us the images of the three autochthonous viper species that appear in the article.

This work is a partial result of the research agreement signed between the Instituto de Salud Carlos III and Instituto Bioclon S.L. de C.V. partially funded by "Fondo de Cooperación Internacional en Ciencia y Tecnología entre México y la Unión Europea" (FONCICYT) (application number 93608). It is part of a research project (ref. PI08/ 90612) of the Spanish National R\&D plan. The funders had no role in study design, data collection and analysis, decision to publish, or preparation of the manuscript.

\section{Ethical statement}

Our article entitled: "Approach to the epidemiology of venomous bites in Spain" follows all Ethical guidelines for journal publication given in the following links provided on your webpage: http://www.elsevier.com/publishingethics and http://www.elsevier.com/ethicalguidelines.

\section{Conflict of interest}

There are no competing interests.

\section{References}

Brito, J.C.A.R., 2009. Víbora cantábrica - Vipera seoanei. In: Salvador, A., Marco, A. (Eds.), Enciclopedia Virtual de los Vertebrados Españoles. Museo Nacional de Ciencias Naturales, Madrid. http://www. vertebradosibericos.org/.

Brito, J.C.A.R., 2011. Víbora hocicuda - Vipera latastei. In: Salvador, A., Marco, A. (Eds.), Enciclopedia Virtual de los Vertebrados Españoles. Museo Nacional de Ciencias Naturales, Madrid. http://www. vertebradosibericos.org/.

Chippaux, J.P., 2012. Epidemiology of snakebites in Europe: a systematic review of the literatura. Toxicon 59, 1-14.

Duguy, R., Saint-Girons, H., 1976. Le statut de Vipera seoanei Lataste, 1879. Bull. Soc. Zool. Fr. 101, 729-730.

Martínez-Freiría, F., 2009. Víbora áspid - Vipera aspis. In: Salvador, A., Marco, A. (Eds.), Enciclopedia Virtual de los Vertebrados Españoles. Museo Nacional de Ciencias Naturales, Madrid. http://www. vertebradosibericos.org/.

Petite, J., 2005. Viper bites: treat or ignore? Review of a series of 99 patients bitten by Vipera Aspis in alpine Swiss area. Swiss Med. Wkly. $135,618-625$.

Prenzel, F., Schulz, M., Siekmeyer, W., Rahn, W., Kiess, W., 2008. Adder bites-clinical picture, diagnosis and management. Dtsch. Med. Wochenschr. 133 (20), 1075-1080.

Saint-Girons, H., Duguy, R., 1976. Écologie et position systématique de Vipera seoanei Lataste, 1879. Bull. Soc. Zool. Fr. 101, 325-339. 